\title{
APROXIMAÇÕES ENTRE O TEXTO FALADO E O TEXTO ESCRITO (LITERÁRIO): A CONSTRUÇÃO DA ORALIDADE EM “CORAÇÃO DE MÃE” DE RUBEM BRAGA
}

\author{
Carolina dos Santos Rocha ${ }^{1}$ \\ Maria José Gordo Palo
}

\begin{abstract}
Resumo: Tendo como ideal a objetividade, o texto escrito pode, principalmente na modalidade literária, aproximar-se do texto oral, por meio de recursos textuais como a pausa, tópicos, subtópicos e digressões. Este artigo investiga estas aproximações apresentando em análise a crônica "Coração de mãe" de Rubem Braga publicada na antologia Morro do Isolamento. Apresentamos suporte teórico que discute as duas modalidades, o texto falado e o texto escrito literário e, entre as referências, destacamos, Dino Preti e Hudinilson Urbano.
\end{abstract}

Palavras-Chave: Oralidade. Crônica. Rubem Braga.

\section{APPROCHES BETWEEN THE ORAL TEXT AND WRITTEN TEXT (LITERARY): THE CONSTRUCTION OF THE ORALITY IN “CORAÇÃO DE MÃE” OF RUBEM BRAGA}

\begin{abstract}
In order to achieve objectivity the written text can, especially in the literary mode, approach the oral text through textual features such as pause, topics, subtopics and digressions. This article intends to investigate these approaches through a chronicle's analysis "Coraçao de Mãe “, by Rubem Braga, published in the anthology "Morro do Isolamento". For this, we present theoretical support discussing the two modes, the oral text and written literary text, among references highlight Dino Preti and Hudinilson Urbano.
\end{abstract}

Keywords: Orality. Chronicle. Rubem Braga.

\footnotetext{
${ }^{1}$ Mestranda no Programa de Estudos Pós-Graduados em Literatura e Crítica Literária da Pontifícia Universidade Católica de São Paulo (PUC-SP); Bacharel e Licenciada em Letras - Universidade de São Paulo (USP-SP). Endereço eletrônico: carolrocha83@yahoo.com.br.

2 Professora Doutora do Programa de Estudos Pós-Graduados em Literatura e Crítica Literária (PUC-SP). Endereço eletrônico: mpalo@terra.com.br.
} 


\section{Introdução}

Por que, em alguns textos literários, é possível perceber uma aproximação com a cultural oral que atravessa gerações através da literatura? Quais elementos linguísticos o texto literário nos oferece que o aproxima desta cultura primordial? Quais elementos comuns existem entre textos orais e o texto literário? Este trabalho visa responder essas perguntas sob a perspectiva teórica discutida por alguns autores, entre eles, Dino Preti (2004) e Hudinilson Urbano (2000).

Para análise de Coração de Mãe, crônica de Rubem Braga, foi adotado o princípio que afirma a ideia de continuum entre o texto falado e o texto escrito (NEVES, 2012), ou seja, um texto não pode ser definido puramente como "oral" (falado) ou como puramente escrito (elaborado) uma vez que elementos linguísticos comuns permeiam um e outro, como por exemplo, a presença de um interlocutor: quem fala/escreve pressupõe um interlocutor/leitor. Esta perspectiva problematiza um ponto de vista tradicionalista que separava dicotomicamente o texto escrito do texto falado, por meio de alguns recursos linguísticos. Apontamos como exemplo desta perspectiva tradicionalista os manuais de redação para uso jornalístico, pois atendendo à premissa de evitar a oralidade, recomendam a objetividade por meio de frases curtas e que contenham uma só ideia ${ }^{3}$. No entanto, a análise da crônica "Coração de mãe" demonstra que é possível desenvolver um tópico (tema central) e seus subtópicos, como acontece na língua falada, sem perder a objetividade traduzida na elaboração literária.

Este estudo também faz uma análise dos elementos ditos propriamente literários - personagens, narrador e autor (extraliterário) uma vez que, é por meio da construção desses elementos que a intenção do texto é revelada: aparentemente escrita como uma conversa, o gênero textual “crônica" traz temas universais para serem discutidos.

\footnotetext{
3 Manual de redação Folha de S. Paulo disponível em http://www.acmcomunicacao.com.br/wpcontent/midias/Manual-de-Redacao-Folha-de-SP.pdf. Acesso em 06 ago. 2016.
} 


\section{O gênero textual "crônica"}

Na antologia Morro do isolamento, com crônicas datadas de setembro de 1934 a abril de 1945, foi publicada a crônica Coração de Mãe de Rubem Braga, objeto deste estudo. Nela, o narrador introduz sua narrativa em tom de "causo", dizendo que não vai contar certos detalhes do acontecido: aqui está em jogo o dizere o não dizer, pois em um tom de uma fofoca, a crônica tem inicio: "O nome da rua eu não digo, e o das moças muito menos". O caso é que o narrador, morador do Catete, deve contar a confusão ocorrida entre duas moças - Marina e Dorinha - e a sua mãe, todas vivem em uma pensão no Catete. Este é o tema principal da crônica.

O anonimato, de um lado, é um traço do gênero “crônica”, um recurso que tanto serve para aproximar o leitor como numa roda de conversa, quanto prefacia um tema complexo sobre aparência de conversa fiada, termo usado por Antônio Cândido (1992) em A vida ao rés-do-chão. Por outro lado, como em Coração de Mãe, o causo popular também tem como traço característico o anonimato, o que aproxima a crônica de Braga à cultura oral: as primeiras narrativas eram transmitidas de boca em boca e proporcionavam um ensinamento, uma reflexão. O jogo linguístico construído na narrativa contradiz o narrador quando afirma o não dizer, pois informa ao leitor vários detalhes sobre o "causo", como por exemplo, a fama posterior adquirida pelas moças como cantoras do rádio, o nome da rua, do bairro e das moças.

Outro traço formador da crônica é o flagrante do cotidiano, uma vez que, o texto é encomendado pelo jornal e deve atender ao "furo" jornalístico, narrando algo inesperado que prenda a atenção do leitor. Sobre esse aspecto, Arriguchi, em Braga de novo por aqui e Fragmentos sobre a crônica (1987, p. 35) comenta: “[...] os olhos do cronista treinado no jornal para o flagrante do cotidiano, afeitos à experiência do choque inesperado em qualquer esquina, estão preparados em meio à vida fragmentária, aleatória e fugaz dos tempos modernos, para a caça de instantâneos".

Por outro lado, a crônica deve atender também aos traços definidores da literariedade enquanto gênero. Esse viés literário também foi comentado pelo crítico citado acerca da obra de Rubem Braga, cronista nato: "Não raro ela adquire assim, entre nós, a espessura de texto literário, formando-se pela 
elaboração da linguagem, complexidade interna pela penetração psicológica e social, pela força poética ou pelo humor, uma forma de conhecimento de meandros sutis de nossa realidade e, de nossa história" (ARRIGUCHI, 1987, p. 53).

Entre comentários e reflexões acerca da vida, o narrador de Coração de Mãe convida o leitor a percorrer sobre outros assuntos desta conversa elaborada: um céu azul que não pertence ao bairro ou sobre a cidade de Niterói ou, ainda, refletir sobre a linguagem utilizada pelos personagens deste causo escrito.

Com ares de passeio pelo bairro do Catete, tal e qual um turista, o leitor é conduzido, chegando ao final da leitura surpreendido com a ressignificação do clichê "coração de mãe”: uma mãe, aparentemente imoral, se mostra ofendida com a falta de moral das filhas e as recolhe novamente à pensão da qual as expulsara em nome dos bons costumes. Os ditados populares coração de mãe não se engana e no coração de mãe sempre cabe mais um parecem permear a intriga deste texto elaborado de maneira irônica: as moças, Dorinha e Marina aparentemente não fizeram nada grave, mas a mãe - por ter um coração que não se engana - as expulsa, aliás, sobre isso, diz o narrador: “coração de mãe é aflito e severo" [linha 36]. A pensão, como coração de mãe, está sempre movimentada, "pululante de funcionários, casais, estudantes, senhoras bastante desquitadas" [linha 9].

Segundo Maria Helena Moura Neves em As estratégias discursivas e suas implicações na relação entre oralidade e escrita - um estudo do parêntese na crônica (2012), a crônica é um gênero textual com alto nível de contextualização. Ligada sempre ao cotidiano, a crônica pode revelar os costumes da época e traz ainda, afirma a autora, forte engajamento pessoal: "uma crônica deixa ver quem a cria, traz sua perspectiva, sugere seus interesses sem necessariamente revelar o próprio autor e ao mesmo tempo, engaja o leitor mediante comunhão de interesses" (NEVES, 2012, p. 6). Sendo assim, ao analisarmos o papel da mulher da década de 40 (época que foi publicada a crônica) - mantenedora do lar, amorosa e dedicada - em contraponto ao retrato na crônica analisada, a mãe de Coração de Mãevai à contramão de tudo isso: segundo o narrador, Dona Rosalina age como um elefante (“A conversa foi 
interrompida da maneira pela qual um elefante interromperia a palestra amorosa de dois colibris na relva"), [linha 44], com fúria ("veio uma palavra que elevou dona Rosalina ao êxtase da fúria",) [linha 54], faz um discurso violento ("Nessa porta dona Rosalina fez um comício [...] foi das coisas mais violentas que já se disseram em público neste país") [linha 69] e, finalmente "agarra as filhas pelos braços” (“desceu feito uma fúria, abriu caminho na massa compacta e agarrou as filhas pelos braços, gritando") [linha 122].

Desta reflexão sobre o papel social "mãe" e os valores morais da época que o cercam, a crônica de Rubem Braga transcende o circunstancial - narrar um "causo" - com o desfecho em tom reflexivo: "não há nada, neste mundo, como o coração de mãe" [linhas 125 e 126], finaliza o narrador. Sobre esse aspecto, afirma Jorge de Sá, em A Crônica (2005, p. 20): “imitando a estrutura de conversas, o cronista começa a falar de um tema (ou subtema) e acaba nos conduzindo a outro tema bem mais complexo, embora nem sempre percebido por nós".

\section{O narrador}

Em Coração de Mãe, o narrador em primeira pessoa com ciência parcial dos fatos divide-se em I. narrar o acontecido, por vezes dando voz ao personagem em discurso direto; II. expor sua opinião acerca das personagens, cito: "A tendência das moças detentoras de olhos azuis é para ver a vida azul celeste; e dos canários é voar” ou ainda em “[...] mas o coração das mães é aflito e severo" e; III. como personagem coadjuvante como podemos verificar em “[...] nós, do Catete, somos verdadeiros gentlemen". Portanto, enquadrá-lo apenas como um narrador em $1^{a}$ pessoa não descreveria suas múltiplas funções.

Segundo Hudinilson Urbano (2000), o enunciador do discurso se desdobra em autor, peça extradiegética e, em narrador, delegado do autor e encarregado dos conteúdos narrados. Ao autor, cabe a escolha da história, o planejamento, a organização estrutural e a intenção. Assim, ao ler Coração de Mãe é possível inferir que o texto tenha sido elaborado para, primeiramente, narrar um causo e, também, comentar ou refletir acerca dos papéis sociais representados àquela época: a mãe e as filhas. Para confirmar essa hipótese, é 
possível analisar a linguagem: apropriada para ambientar o leitor na cenografia da fofoca em uma pensão, moradia popular. Para isso, o autor que é extradiégetico escolhe alguns recursos sonoros, sinais de pontuação e construção sintática com base em adjetivos, que tornam a linguagem mais popularesca, com um ritmo próprio de fala.

\section{As personagens}

O narrador apresenta as personagens centrais deste "causo": duas moças loiras e cantoras, Dorinha e Marina, e sua mãe, Dona Rosalina. As moças falam em discurso direto em dois momentos apenas: "Pois é... a velha é muito cacete. Não, não liga a isso não. É cretinice da velha, mas a gente tapeia. Olha nós vamos ao dentista às 5 horas. É....” e, “E a senhora também! Pensa que estou disposta a viver ouvindo desaforo? A senhora precisa deixar de ser...." [linhas 41, 42, 51, 52 respectivamente]. Em discurso direto, a personagem Dona Rosalina, a mãe, apresenta-se em três momentos: “Fora! Para fora daqui, todas duas!”, “Passem já! Vão fazer isso assim assim, vão para o diabo que as carregue, suas assim assim! Não ponham mais os pés em minha casa!"e, finalmente em “Passem já para dentro suas desavergonhadas!" [linhas 56, 62, 63, 124 respectivamente].

Os verbos introdutórios das falas de Dona Rosalina parecem traduzir sua personalidade forte e autoritária. São eles: “vociferar" (“A velha vociferava que aquilo era uma vergonha") [linha 46]; "berrava” ("ao mesmo tempo que dona Rosalina berrava") [linha 55] e "gritava" ("Outras palavras foram gritadas", diz o narrador e "agarrou as filhas pelos braços, gritando") [linhas 60 e 123 respectivamente]. Destaco ainda os verbos que descrevem as ações de Dona Rosalina e os elementos descritivos (adjetivos e complementos nominais) que contribuem na construção de sua personalidade: "preferia matar aquelas duas pestes”, “[... ] elevou Dona Rosalina ao êxtase da fúria” [linha 54], “as moças foram empolgadas em um redemoinho de tapas e pontapés” [linha 55]. A mãe, diferente dos padrões de recato e discrição da época, faz um comício e, empurra as filhas porta a fora de casa. 
É importante também, destacar a intervenção do narrador no discurso direto deste personagem: quando Dona Rosalina expulsa as moças de casa, "vocifera" algo indizível - provavelmente palavrões - o narrador então substitui a palavra indizível por "isso assim assim" ("Vão fazer isso assim assim, vão para o diabo que as carregue, suas assim assim!") [linhas 62 e 63 respectivamente] criando um tom jocoso e curioso. Tal intervenção expõe a elaboração do texto e a preocupação com a verossimilhança, pois numa discussão dificilmente alguém diria "assim assim" no lugar de um palavrão. No entanto, ao reproduzir um acontecido, passar a diante uma fofoca, o locutor pode fazer essa substituição por pudor ou para atenuar a força das palavras utilizadas pela senhora.

Por outro lado, os modalizadores ${ }^{4}$, elementos descritivos que acompanham as ações das moças, parecem demonstrar uma personalidade sedutora. Estão assim no texto: "com voz muito doce" e, "Houve ligeira reação partida de Marina, assim articulada", sendo que ligeira pode ser a maneira como a moça se defendeu, rápida, ou ainda pode ser entendido como breve, curta articulação e comprovaria a hipótese de que a moça carrega certa astúcia, é maliciosa. Todavia, embora, os verbos introdutores de fala destas moças sejam mais amenos que os da mãe, as falas propriamente ditas revelam certa insubordinação ou desobediência, marcas de uma personalidade forte: “Pois é... a velha é muito cacete" [linha 41] diz Dorinha e Marina: "Pensa que estou disposta a viver ouvindo seus desaforos?" [linha 51].

Os outros personagens, secundários, não são apresentados em discurso direto e tampouco em discurso indireto, exceto em "Em certo momento um caixeirinho do armazém disse que", [linha 102]. Porém, os verbos que descrevem as ações dos homens são bastante significativos. Solidários às moças, esses homens revelam cenas de gentilezas em excesso. Os verbos que destaco são:

- "sugerir", duas vezes [linhas 82 e 105, respectivamente]: [...] o precursor aproximou-se de Marina e sugeriu que em sua pensão[...] havia dois quartos ${ }^{4}$ Entendido como estratégia linguística discursiva que está a serviço da manifestação de subjetividade do
enunciador. 
vagos / Um jovem oficial do gabinete do Ministério da Agricultura sugeriu que elas fossem para casa de sua irmã; - "propor", duas vezes [linhas 85 e 95, respectivamente]: Um segundo a esse tempo sitiava Dorinha, propondo chamar um táxi[...]/[...] um estudante de medicina [...] tomou coragem epropôs conduzi-las para o Uruguai.

- $\quad$ "oferecer", quatro vezes [linhas 87, 93, 103 e 108] e seu sinônimo "ofertar" [linha 107]: [...] alguns presentes, que ofereceram bons carros particulares / Um bacharel pela Faculdade de Niterói [...] ofereceu-se, não obstante, para levar os dois canários / Essa ideia brilhante de oferecer uma proteção de toda família venceu em toda linha / [...]um bancário, intrépido, ofereceu três mães, à escolha; [...]com um gesto largo ofertando-lhes a proteção de sua própria mãe, dele.

- $\quad$ "indicar" [linha 106] Um doutorando indicou a residência de sua irmã casada [...];

- "conduzir" [linha 119]: até o motorista da Limpeza Pública quis à viva força conduzi-las para a boléia do grande caminhão;

- $\quad$ E por fim, diz o narrador, todos os personagens masculinos "procuravam passar a mão pelas cabeças das mocinhas" [linha 113]: $O$ mais comovente era ver como todos aqueles bons homens procuravam passar a mão pelas cabeças das mocinhas [...].

A construção do texto com estes verbos e seus complementos em contraponto ao ocorrido - oculto ao leitor - levam à dúvida: as moças são de fato inocentes? A mãe tem razão? Por que ou para quê os homens são tão gentis?

\section{A construção da oralidade}

Quanto à sonoridade, as expressões populares e as aliterações reproduzem um ritmo de fala respectivamente em, "pardieiro pardarrão"; "andanças e parranças", "tropos que tais" e; em "verdades muito duras foram proferidas em voz muito alta. A velha vociferava que aquilo era vergonha [...]”; 
Ainda no exercício da linguagem, o autor se vale do uso do exagero, típico do discurso da fofoca: "De todos os lados apareceram os mais bondosos homens - funcionários, militares, estudantes, bacharéis, engenheirossanitários, jornalistas, comerciários, sanitaristas e atletas - fazendo os mais tocantes oferecimentos". Ou com uso de intensificadores em, "[...] foi das coisas mais violentas que já se disseram em público neste país". Também utiliza adjetivos talvez para intensificar as "cores" da fofoca, por exemplo, no uso metafórico de "Creio ser inevitável dizer que eram como dois excitantes e leves canários belgas a saltitar em feio e escuro viveiro". Enfim, o cenário é vivo: uma casa de pensão lotada habitada, pelos mais diferentes tipos populares, onde a privacidade e a intimidade não são valores preservados.

Quanto ao uso das reticências, elemento linguístico que marca uma aproximação com a oralidade porque pode indicar pausa - típico da fala - há três ocorrências com funções diferentes no texto:

- $\quad$ Em discurso direto, servem para indicar uma pausa para elaboração e/ou introdução de uma nova fala: Pois é... a velha é muito cacete / A senhora precisa deixar de ser... “.

- Na fala do narrador, atuam como item de elaboração do seu discurso: A velha ... Essa expressão malazada foi o princípio da tormenta.

A respeito da parentetização, Neves (2012) afirma que a ocorrência desse recurso no texto escrito pode ser visto sob duas perspectivas: do ponto de vista da língua falada, os parênteses são semelhantes às pausas realizadas na enunciação e, sob o ponto de vista da língua escrita, o uso da parentetização pode ser interpretado como uma marcação de estilo. Durante a leitura da crônica é possível perceber que, a primeira e a segunda ocorrência imprimem uma cadência na progressão narrativa, alterando o ritmo da leitura, impô-lo uma pausa. Essa pausa "obrigatória" aumenta as expectativas do leitor, em relação ao desfecho da intriga narrada e, revela um trabalho de elaboração feito pelo autor com objetivo de manter a atenção do leitor. Essas ocorrências também podem indicar ocorrências de digressões dentro dos tópicos discursivos, sob o ponto de vista do texto oral, pois o tópico - aquilo acerca do que se fala, segundo Fávero (2003) - neste caso é a intriga entre mãe e filhas. 
Sendo assim, a parentetização é mais um recurso linguístico que aproxima texto escrito ao texto oral.

Na crônica em análise são três ocorrências dos parênteses. Segundo Neves (2012) esse recurso linguístico utilizado na crônica pode ser interpretado como um índice de aproximação com a oralidade, uma vez que, por meio dos parênteses, o autor busca interagir com o leitor. Em Coração de Mãe ocorrem dois usos diferentes de parênteses:

a) A parentetização com foco na elaboração do conteúdo em ("Niterói, Niterói, como és formosa", suspirou um poeta do século passado, o que foi o dos suspiros) e, em ("Todas as duas" é um galicismo, conforme algum tempo depois observou um leitor da Gramática Expositiva Superior de Eduardo Carlos Pereira, residente naquela pensão, em palestra com alguns amigos).

b) A parentetização com foco no interlocutor em: (O leitor inteligente substituirá as expressões "isso assim assim" pelos termos convenientes; a leitora inteligente não deve substituir coisa alguma para não ficar com vergonha).

Em “O tópico discursivo”, Fávero (2003, p. 59) afirma que a digressão é definida por "uma porção de conversa que não se acha diretamente relacionada com o tópico em andamento". Como vimos, o tópico da crônica Coração de Mãe é a discussão entre mãe e filhas. Com a pretensão de narrar o que aconteceu na pensão do Catete, o narrador, em clima de conversa com seu leitor, faz algumas digressões que se relacionam com o conteúdo.

Já no terceiro parágrafo, ao narrar sobre o cotidiano incompatível com a vida das moças aspirantes à carreira artística, um longo período digressivo inicia e, se estende ao quarto parágrafo. O narrador começa a discorrer sobre o céu azul do bairro, passa por discussões bairristas entre Niterói e Rio de Janeiro e culmina, no quarto parágrafo com a citação do verso adaptado pelo narrador "Caramuru, Caramuru, filho do fogo, mãe da Rua Lopes Trovão" (no original, verso de Frei José Santa Rita Durão, apresenta-se como filho do trovão). Em “'Niterói, Niterói', como és formosa, suspirou um poeta do 
século passado, que foi o dos suspiros" [linhas 22 e 23], o autor utiliza o recurso do intertexto: a citação é do verso de Gonçalves de Magalhães que, em polêmica com José de Alencar ficou conhecido como poeta dos suspiros. Neste poema Confederação dos Tamoios, o poeta enaltece a cidade de Niterói, no episódio que narra a guerra entre os índios Tupinambás e os colonizadores.

É possível perceber, no terceiro e quarto parágrafos, algo comum: um clima nostálgico em relação à cidade de Niterói e ao bairro do Catete. A biografia do autor físico "Rubem Braga", conceito definido por Urbano (2000) como a pessoa física do autor e, não necessariamente de um texto ou de obra determinada, informa que o referido cronista, natural de Cachoeiro do Itapemirim, morou em Niterói antes de concluir seus estudos na grande capital, Rio de Janeiro.

Mais adiante, no décimo segundo parágrafo, uma pequena descrição do bairro parece prefaciar um subtópico ${ }^{5}$ importante na progressão narrativa: o cavalheirismo do bairro do Catete. Cito: “Gente muito misturada, etc. É assim que os habitantes dos bairros menos precários costumam falar mal de nosso Catete. Mas uma coisa ninguém pode negar: nós, do Catete, somos verdadeiros gentlemen" [linhas 76,77 e 78]. Os grifos nos pronomes revelam um posicionamento: o narrador também é do bairro, possivelmente um expectador.

\section{Considerações finais}

Este estudo procurou analisar o texto literário “crônica" em Coração de Mãe de Rubem Braga sob perspectiva teórica discutida por alguns autores, entre eles, Dino Preti (2004) e Hudinilson Urbano (2000). A fim de buscar elementos linguísticos comuns à língua falada e à língua escrita, a análise procurou respeitar as particularidades das distintas modalidades, tendo em vista que, o texto escrito não pode representar de maneira idêntica à fala, segundo afirma Preti (2004). Embora, possam ter recursos semelhantes, como as pausas, o tópico, os subtópicos e as digressões, as funções que esses recursos

\footnotetext{
${ }^{5}$ Segundo Fávero (2003, p. 54), o subtópicos está estruturado como um constituinte mínimo e, o tópico seria uma porção maior.
} 
desempenham são diferentes, posto que são ocorrências elaboradas para atingir o efeito da naturalidade da fala, conforme o registro: texto literário e a interação propriamente dita.

Em contrapartida a um ponto de vista tradicionalista, que opunha o texto escrito ao texto falado, trazer a nomenclatura linguística comum à análise de textos orais ao texto literário proporcionou um olhar minucioso e atento na busca de aproximações com a oralidade. Foi possível perceber, por meio de levantamento de elementos linguísticos - verbos, adjetivos, expressões populares, sonoridades, sinais de pontuação, turnos e digressões que a crônica de Rubem Braga vai à fonte do que chamamos hoje de literatura: a transmissão de narrativas ficcionais de geração a geração, com o sabor da oralidade.

Sob ponto de vista da análise linguística, as instâncias literárias, conforme Urbano (2000) - narrador e personagens - foram brevemente analisadas, por meio de suas ações e dos verbos introdutores de fala, bem como o papel do autor, peça extradiégetica: indícios de sua marca do texto literário.

Certamente, as possíveis leituras de Coração de Mãe não se esgotam neste artigo que, pode ser ampliado posteriormente. No entanto, é importante ressaltar o trabalho científico de investigação com base em respeitada bibliografia e rigor de análise.

\section{Referências}

ARRIGUCHI JÚNIOR, Davi. Braga de novo por aqui e Fragmentos sobre a crônica. In: Enigma e Comentário. ensaios sobre literatura e experiência. São Paulo: Cia das Letras, 1987, 29-69.

BRAGA, Rubem. Coração de mãe. In: 200 crônicas escolhidas. Rio de Janeiro: Record, 2008.

CANDIDO, Antonio et al. A vida ao rés do chão. In: A crônica: o gênero, sua fixação e suas transformações no Brasil. Rio de Janeiro: Fundação Casa de Rui Barbosa, 1992, 13-22. 
NEVES, Maria Helena de Moura. As estratégias discursivas e suas implicações na relação entre oralidade e escrita - um estudo do parêntese na crônica. Linguística, v. 27, n. 1. Montevidéu, jun. 2012, p. 77-97.

FÁVERO, Leonor Lopes. O tópico discursivo. In: PRETI, Dino (Org.). Análise de textos orais. São Paulo: Humanitas, 2003, p. 39-46.

PRETI, Dino. Capítulo 12. Diálogo de ficção e realidade linguística \& Capítulo 13. Oralidade e narração literária. In: Estudos da língua oral e escrita. Rio de Janeiro: Lucerna, 2004.

SÁ, Jorge de. A crônica. 6. ed. São Paulo: Ática, 2005.

URBANO, Hudinilson. Narrativa Oral / Narrativa escrita (literária). In: Oralidade na literatura: o caso de Rubem Fonseca. São Paulo: Cortez, 2000, p. 35-71.

\section{Anexo}

\section{Coração de Mãe}

1. O nome da rua eu não digo, e o das moças muito menos. Se me perguntarem se 2. isso não aconteceu na Rua Correia Dutra com certas jovens que mais tarde vieram a 3 . brilhar no rádio eu darei uma desculpa qualquer e, como meu cinismo habitual, 4. responderei que não.

5. As moças eram duas, e irmãs. A mãe exercia laboriosas funções de dona de 6. pensão. Uma senhora que é dona de pensão no Catete pode aceitar depois 7. indiferentemente um cargo de ministro da guerra da Turquia, restauradora das 8. finanças do Reich ou poeta português. A pensão da mãe das moças era uma grande 9. pensão, pululante de funcionários, casais, estudantes, senhoras bastante desquitadas. E 10. não devo dizer mais nada: quanto menos se falar da mãe dos outros, melhor. Juntarei 11. apenas que essa mãe era muito ocupada e que as moças possuíam, ambas, olhos 12. azuis. No pardieiro pardarrão, tristonho, as duas meninas louras viviam cantarolando. 13. Creio ser inevitável dizer que eram como dois excitantes e leves canários-belgas a 14. saltitar em feio e escuro viveiro - e a mãe era muito ocupada.

15. A tendência das moças detentoras de olhos azuis é para ver a vida azul-16. celeste; e as dos canários é voar. Mesmo sobre casarões do Catete o céu às vezes 17. azul, e o sol acontece de ser louro. Uns dizem que na verdade esse azul celeste não 18. pertence ao Catete e sim ao Flamengo: a população do Catete apenas o poderia olhar 19. de empréstimo. Outros afirmam que o sol louro é o da circunscrição de Santa Teresa 20. e da paróquia de Copacabana; nós, medíocres e amargos homens do Catete, também 21. o usufruiríamos indebitamente. Não creio em nada disso. A mesma injúria assacaram 22. contra Niterói ("Niterói, Niterói, como és formosa", suspirou um poeta do século 23. passado, que foi o dos suspiros) declarando que Niterói não tem lua 
própria, e a que 24. ali é visível é de propriedade do Rio. Não, em nada disso creio. Em minhas andanças 25. e parranças já parei em Niterói, onde residi na Rua Lopes Trovão, e recitava 26. habitualmente com muito desgosto de uma senhorita vizinha: "Caramuru, Caramuru, 27. filho do fogo, mãe da Rua Lopes Trovão!"

28. Já não me lembro quem me ensinou esses versinhos, aliás mimosos. Ainda 29. hoje costumo repeti-los quando de minhas pequenas viagens de cabotagem, jogando 30. miolo de pão misto às pobres gaivotas.

31. Ora, aconteceu que uma noite, ou mais propriamente, uma madrugada, a mãe 32. das moças de olhos azuis achou que aquilo era demais. Cá estou prevendo o leitor a 33. perguntar que "aquilo" é esse, que era demais. Explicarei que Marina e Dorinha 34. haviam chegado em casa um pouco tontas, em alegre e promíscua baratinha. 35. Certamente nada acontecera de excessivamente grave - mas o coração das mães é 36. aflito e severo. Aquela noite nenhum dos hóspedes dormiu: houve um relativo 37. escândalo e muitas imprecações.

38. No dia seguinte pela manhã aconteceu que Marina estava falando ao telefone 39.c om voz muito doce e dona Rosalina (a mãe) chegou devagarinho por detrás e ouviu 40. tropos que tais:

41. - Pois é.... a velha é muito cacete. Não, não liga a isso não. É cretinice da 42. velha, mas a gente tapeia. Olha, nós hoje vamos ao dentista às 5 horas. É...

43. "A velha..." Essa expressão mal-azada foi o princípio da tormenta. A 44. conversa telefônica foi interrompida da maneira pela qual um elefante interromperia 45. a palestra amorosa de dois colibris na relva. Verdades muito duras foram proferidas 46. em voz muito alta. A "velha" vociferava que aquilo era uma vergonha e preferia 47. matar aquelas duas pestes a continuar aquele absurdo. "Maldita hora - exclamou - 48. em que teu pai foi-se embora." Assim estavam as coisas quando Dorinha apareceu 49. no corredor - e foi colhida ou colidida em cheio pela tormenta. Houve ligeira reação 50. partida de Marina, assim articulada:

51. - E a senhora também! Pensa que estou disposta a viver ouvindo desaforos: A 52. senhora precisa deixar de ser...

53. Depois do verbo "ser" veio uma palavra que elevou dona Rosalina ao êxtase 54. da fúria. As moças foram empolgadas em um redemoinho de tapas e pontapés escada 55. abaixo, ao mesmo tempo que dona Rosalina berrava:

56. - Fora! Para fora daqui, todas duas!

57. "Todas suas" é um galicismo, conforme algum tempo depois observou um 58. leitor da Gramática Expositiva Superior de Eduardo Carlos Pereira, residente 59. naquela pensão, em palestra com alguns amigos.)

60. Outras palavras foram gritadas em tão puro e rude vernáculo que tentarei 61. traduzi-las assim: 
62. - Passem já! Vão fazer isso assim assim, vão para o diabo que as carregue, 63. suas isso assim assim! Não ponham mais os pés em minha casa!

64. (O leitor inteligente substituirá as expressões "isso assim assim" pelos termos 65. convenientes; a leitora inteligente não deve substituir coisa alguma para não ficar 66. com vergonha.)

67. As moças desceram até o quarto sob intensa fuzilaria de raiva maternal, 68. arrumaram chorando e tremendo uma valise e se viram empurradas até a porta d rua. 69. Nessa porta dona Rosalina fez um comício que, mesmo contando os discursos do Sr. 70. Maurício de Lacerda na Primeira República e os piores artigos dos falecidos 71. senhores Mário Rodrigues e Antônio Torres produzidos sob o mesmo regime, foi das $\mathbf{7 2}$. coisas mais violentas que já se disseram em público neste país. O café da esquina se 73. esvaziou; automóveis, caminhões e um grande carro da Limpeza Pública 74. estacionaram na estreita rua. As duas mocinhas, baixando as louras cabeças, $\mathbf{7 5}$. choravam humildemente.

76. Gente muito misturada, etc. É assim que os habitantes dos bairros menos 77. precários e instáveis costumam falar mal de nosso Catete. Mas uma coisa ninguém 78. pode negar: nós, do Catete, somos verdadeiros gentlemen. $\mathrm{O}$ cavalheirismo do bairro 79. se manifestou naquele instante de maneira esplendente quando a senhora dona 80. Rosalina deu por encerrado, com ríspido palavrão, o seu comício.

81. Em face daquelas mocinhas expulsas do lar e que soluçavam com amargura 82. houve um belo movimento de solidariedade. Um cavalheiro - o precursor 83. aproximou-se de Marina e sugeriu que em sua pensão, na rua Buarque de Macedo, 84. havia dois quartos vagos, e que elas não teriam de pensar no pagamento da quinzena. 85. Um segundo a esse tempo sitiava Dorinha, propondo chamar um táxi e leva-la para 86. seu apartamento, onde ela descansaria, precisava descansar, estava muito nervosa. A 87. ideia do táxi revoltou alguns presentes, que ofereceram bons carros particulares.

88. De todos os lados apareceram os mais bondosos homens - funcionários, 89.militares, estudantes, médicos, bacharéis, engenheiros sanitários, jornalistas, 90. comerciários, sanitaristas e atletas - fazendo os mais tocantes oferecimentos.

91. Um bacharel pela Faculdade de Niterói (então denominada "a Teixeirinha"), 92. que morava na própria pensão de dona Rosalina e que havia três meses não podia 93. pagar o quarto, ofereceu-se, não obstante, para levar os dois canários até São Paulo, 94. onde pretendia possuir palacete. Ouvindo isso, um estudante de medicina que se 95 . sustentava a médias no Lamas, tomou coragem e propôs conduzi-las para o Uruguai. 99. Seria difícil averiguar por que ele escolheu o Uruguai; naturalmente era um rapaz 100. pobre, com inevitável complexo de inferioridade: ao pensar em estrangeiro não 101. tinha coragem de pensar em país maior ou mais distante.

102. Em certo momento um caixeirinho do armazém disse que as moças 103. poderiam morar com sua prima, em Botafogo. Essa ideia brilhante de oferecer uma 104. proteção feminina venceu em toda linha. Um jovem oficial de gabinete do Ministro 105. da Agricultura sugeriu que elas fossem para casa de uma irmã. Um doutorando 106. indicou a residência de sua irmã casada, e um tenente culminou com um gesto largo 107. ofertando-lhes a proteção de sua 
própria mãe, dele. A luta chegou tal ponto que um 108. bancário, intrépido, ofereceu três mães, à escolha. Em alguns minutos as infelizes 109. mocinhas tinham a sua disposição cerca de quinze primas, vinte e três irmãs 110. solteiras, quatro tias muito religiosas, quarenta e uma irmãs casadas e oitenta e três 111. mães.

112. O mais comovente era ver como todos aqueles bons homens procuravam 113. passar mão pelas cabeças das mocinhas, e lhes dirigiam as palavras mais cheias de 114. ternura e bondade cristã. Trêmulas e nervosas, Marina e Dorinha hesitavam. De 115. qualquer modo a situação havia de ser resolvida. O cavalheiro que tinha conseguido 116. parar o carro em local mais estratégico começou a empurrar docemente as moças 117. para dentro dele, entre alguns protestos de assistência. Vários outros choferes 118. pretenderam inutilmente fazer valer seus direitos - e até o motorista da Limpeza 119. Pública quis à viva força conduzi-las para a boleia do grande caminhão coletor de 120. lixo.

121. Foi então que, subitamente, dona Rosalina irrompeu de novo escada abaixo; 122. desceu feito uma fúria, abriu caminho na massa compacta e agarrou as filhas pelos 123. braços, gritando:

124. - Passem já para dentro! Já para dentro, suas desavergonhadas!

125. Eis o motivo pelo qual eu sempre digo: não há nada, neste mundo, como o 126. coração de mãe.

Recebido em 09 de agosto de 2016.

Aceito em 21 de agosto de 2016. 